\title{
Pancreatic and splenic blastomycosis in an immune-competent woman diagnosed by endoscopic ultrasonography-guided fine-needle aspiration
}

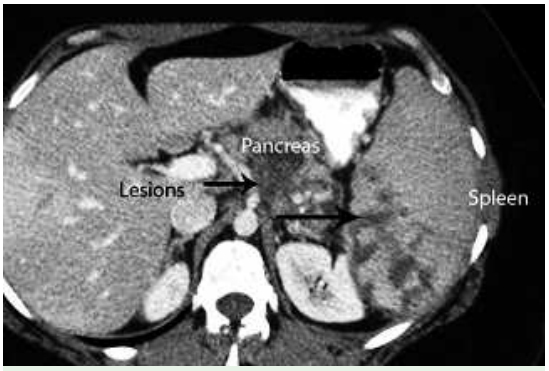

Fig. 1 Abdominal CT scan. The pancreas and spleen are identified. The lesions of interest are shown by black arrows.

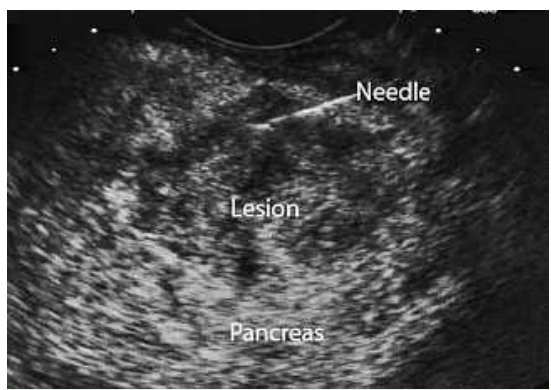

Fig. 2 EUS image of pancreatic lesions during fine-needle aspiration (FNA).

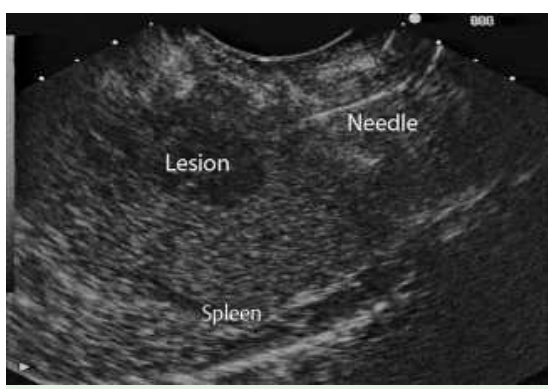

Fig. 3 EUS image of splenic lesions during FNA.

A 36-year-old woman presented with a several-month history of worsening left upper quadrant pain and weight loss. A CT scan showed a pancreatic mass and splenic lesions, and possible splenic vein thrombosis ( Fig. 1). The patient had no history of immunosuppression, diabetes, or HIV. Her physical exam was unremarkable except for left upper quadrant tenderness. Her laboratory tests showed mild microcytic anemia, slight elevation in transaminases, and a two-fold increase in alkaline phosphatase above normal.

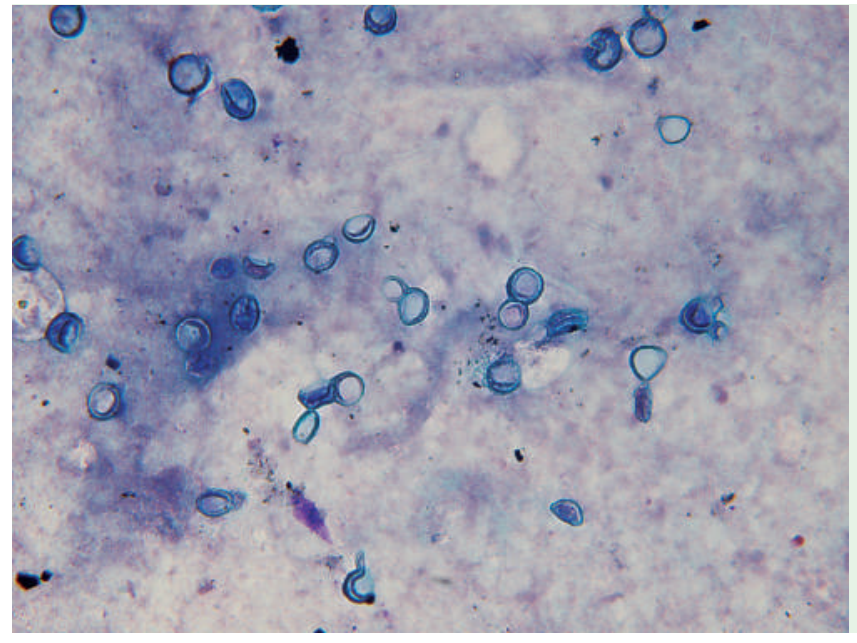

Fig. 4 Initial pancreatic cytology (Diff-Quick preparation). Multiple yeast-like forms are seen in a background of necrosis.

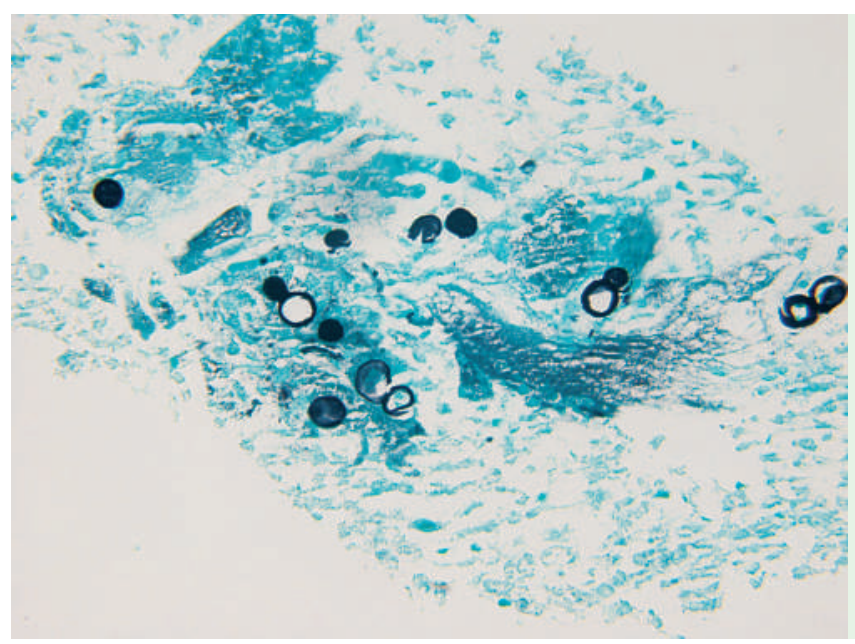

Fig. 5 Confirmatory Gomori methenamine silver (GMS) staining of the splenic aspiration.

Endoscopic ultrasonography (EUS) using Pentax EG 3630 UR and EG 3630 U echoendoscopes revealed a cystic lesion in the pancreas and a hypoechoic lesion in the spleen. Aspiration of the pancreas with a 22-G needle and the spleen with a $25-G$ needle ( $\bullet$ Fig. 2,3 ) revealed necrotic debris and uniform yeast organisms with broad-based budding suggestive of blastomycosis at both sites ( Fig. 4, 5). The presumptive morphological diagnosis was confirmed by culture with DNA probe identification of Blastomyces dermatitidis.

Blastomycosis is an infectious disease caused by the dimorphic fungus Blastomyces dermatitidis $[1,2]$. This disease is endemic to the eastern and central re- gions of North America along the Mississippi, Ohio, and St. Lawrence river valleys. Usually it is a self-limiting pulmonary infection, but systemic spread can occur. Immune suppression does not appear to increase the risk of acquiring disease, but may alter the manifestations [2-4]. For unknown reasons, the disease disseminates in some patients [2-5].

We are unaware of any prior reports of EUS being used to diagnose abdominal involvement in blastomycosis. The use of EUS fine-needle aspiration for diagnosis was ideal in this particular setting since suggestive material was found from both the pancreas and spleen at the time of the procedure, and the diagnosis was confirmed by culture and DNA methodology. 
Endoscopy_UCTN_Code_CCL_1AF_2AZ_3AC

J. C. Deutsch ${ }^{1}$, T. L. Burke' ${ }^{2}$, T. C. Nelson ${ }^{3}$ ${ }^{1}$ Department of Gastroenterology and Cancer Center, St Mary's Duluth Clinic, Duluth, Minnesota, USA

2 Department of Infectious Diseases, St Mary's Duluth Clinic, Duluth,

Minnesota, USA

3 Department of Pathology, St Mary's Duluth Clinic, Duluth, Minnesota, USA

\section{References}

1 Tenenbaum M, Greenspan J, Kerkering TM. Blastomycosis. Crit Rev Microbiol 1982; 9: 139- 163

2 Baumgardner DJ, Buggy BP, Mattson BJ et al. Epidemiology of blastomycosis in a region of high endemicity in north central Wisconsin. Clin Infect Dis 1992; 15: 629-635

3 Pappas PG. Blastomycosis in the immunocompromised patient. Semin Respir Infect 1997; 12: $243-251$

4 Recht LD, Davies SF, Eckman MR, Sarosi GA. Blastomycosis in immunosuppressed patients. Am Rev Respir Dis 1982; 125: 359 362

5 Cano MV, Ponce-de-Leon GF, Tippen S et al. Blastomycosis in Missouri: epidemiology and risk factors for endemic disease. Epidemiol Infect 2003; 131: 907-914
Bibliography

DOI 10.1055/s-2007-966614

Endoscopy 2007; 39: E272-E273

(c) Georg Thieme Verlag KG Stuttgart · New York . ISSN 0013-726X

Corresponding author

\section{J. C. Deutsch}

St Mary's Duluth Clinic

400 East 3rd St

Duluth

MN 55805

USA

Fax: +1-218-786-3019

jdeutsch@smdc.org 